\title{
A AGENDA SOCIAL DO MERCOSUL E SUA REPERCUSSÃO EM TERMOS DE APROFUNDAMENTO \\ E ALARGAMENTO DO BLOCO
}

Karine de Souza Silva

Professora dos Programas de Pós-graduação em Direito (PPGD) e em Relações Internacionais da Universidade Federal de Santa Catarina (PPGRI) da UFSC. Pesquisadora Produtividade Científica do Conselho Nacional de Desenvolvimento Científico e Tecnológico (CNPq). Esta pesquisa foi desenvolvida com apoio do CNPq. E-mail: karine.silva@ufsc.br

\section{Paulo Roberto Ferreira}

Doutorando Direito pelo Programa de Pós-Graduação em Direito da Universidade Federal de Santa Catarina. Professor dos Cursos de Relações Internacionais da Universidade do Vale do Itajaí (UNIVALI) e da Universidade do Sul de Santa Catarina (UNISUL).

\section{Resumo}

O objetivo deste artigo é analisar os níveis de aprofundamento do MERCOSUL, avaliados a partir da inserção de pautas sociais inéditas que, por sua vez, estimularam a fundação de novas instâncias decisórias afirmadoras da autonomia do bloco e propiciaram o alvorecer de uma atmosfera de alargamento e de redefinição da identidade mercosulina. Para tanto, o trabalho divide-se em três partes. Na primeira parte é analisado o aprofundamento institucional do bloco. Em seguida é avaliado a implantaçáo do FOCEM e o aprofundamento da coesáo social. E, por fim, na terceira parte, é discutido o pequeno, mas importante, alargamento. Dentre os resultados do trabalho, está o de que, a despeito do não avanço em termos de integração econômica, o MERCOSUL evoluiu com o advento de novas agendas que não estavam previstas no seu Tratado Constitutivo.

\section{Palavras-chave}

Integração Regional; MERCOSUL; FOCEM.

\section{Resumen}

El propósito de este artículo es analizar la profundización del MERCOSUR, evaluada a partir de la inserción de los nuevos temas sociales que, a su vez, estimularon la 
fundación de nuevas instancias que afirman autonomía del bloque y facilitaron el surgimiento de un ambiente de ampliación y de redefinición de la identidad del Mercosur. Para este fin, el trabajo se divide en tres partes. En la primera parte se analiza la profundización institucional del bloque. En la sección siguiente se evalúa la implementación del FOCEM y la profundización de la cohesión social. Y, por último, en la tercera parte, se discute el alargamiento. En las conclusiones se destaca que a pesar del pequeño avance en términos de la integración económica, el MERCOSUR ha evolucionado en términos sociales con la inserción de nuevas agendas que no estaban previstas en su Tratado Constitutivo.

\section{Palabras clave}

Integración Regional; MERCOSUR; FOCEM.

\section{Introdução}

A trajetória de desenvolvimento do MERCOSUL pode ser, metodologicamente, descrita, em três âmbitos: a) aprimoramento institucional; b) reconhecimento das assimetrias internas e a inserção de ações destinadas à promoção da coesão social; c) o alargamento.

O objetivo deste artigo é analisar os níveis de aprofundamento do MERCOSUL, avaliados a partir da inserção de pautas sociais inéditas que, por sua vez, estimularam a fundação de novas instâncias decisórias afirmadoras da autonomia do bloco e propiciaram o alvorecer de uma atmosfera de alargamento e de redefinição da identidade mercosulina.

Portanto, este trabalho divide-se em três partes. O primeiro item descreve o percurso de desenvolvimento institucional apoiado pelo surgimento de uma nova agenda que impulsiona o reforço à autonomia da Organização internacional. E os dois tópicos seguintes buscam esclarecer o aprofundamento da integração no MERCOSUL através da implantaçáo do FOCEM e do alargamento à entrada de novos Estados-partes.

\section{Aprimorando a Engenharia Institucional}

O nascimento do Mercosul é fruto da reaproximação política entre Brasil e Argentina na década de 1980, no período de redemocratização de ambas naçóes. A partir desta época, as relaçóes entre os dois países se transmutam do eixo confrontação e passam para a cooperaçáo, o que viabilizou a assinatura de uma série de documentos que pavimentaram a avenida que desembocou na criação do Mercosul ${ }^{1}$.

1 Em 19 de outubro de 1979 foi o Acordo Tripartite Brasil-Argentina-Paraguai - Acordo de Aproveitamento Hidrelétrico de Itaipu e Corpus, que versa sobre o aproveitamento dos recursos hidráulicos do Rio Paraná. 
A assinatura, em 1985, da Declaração de Iguaçu, pelos presidentes Raul Alfonsín e José Sarney serviram de bases para a integraçáo ${ }^{2}$ dos Estados do Cone Sul e culminou com a formalização em 1986, do Programa de Interação e Cooperação Econômica. Em 1988, o Tratado de Cooperação e Desenvolvimento previu a criação de uma zona de livre-comércio que se efetivaria no prazo de dez anos ${ }^{3}$. Em $6^{\circ}$ de julho de 1990, Fernando Collor de Mello e Carlos Menem celebraram a Ata de Buenos Aires que visava completar a integração alfandegária binacional através do estabelecimento de um Mercado comum que deveria estar definitivamente conformado em dezembro de $1994^{4}$.

Tal cooperação atraiu a atenção dos vizinhos Uruguai e Paraguai e o desejo de participar da aliança, apesar de uma certa reticência a cerca da liderança brasileira e da posição da Argentina.

A adesão de Paraguai e Uruguai transformou a relação bilateral em um bloco econômico que se consubstanciou na institucionalização de uma Organização Internacional (OI), um marco para a América do Sul, com forte inspiração no modelo de integração regional europeu.

O Tratado de Assunção (TA), assinado em 26 de março de $1991^{6}$ deu vida ao Mercosul. Inicialmente, é relevante observar que o TA nasceu com o objetivo de constituir um Mercado Comum através da implementação da "livre circulação de bens, serviços e fatores produtivos", de "uma tarifa externa comum e uma política comercial comum", da “coordenação de políticas macroeconômicas e setoriais" e da harmonização de legislaçôes nas áreas pertinentes. Como se vê os objetivos ambiciosos que se deveriam ser efetivados em até quatro anos, refletem uma preocupação inicial preponderante econômico-comercial

2 O conceito de integração acolhido neste trabalho é proposto por Mônica Herz e Andreia Ribeiro. Integraçấo significa "um processo dinâmico de intensificação em profundidade e abrangência das relaçôes entre atores levando à criação de novas formas de governança político-institucionais de escopo regional”. HERZ, Mônica; HOFFMANN, Andrea Ribeiro. Organizaçóes internacionais: história e práticas. Rio de Janeiro: Campus, 2004. Cap. 5 p. 168.

3 "O objetivo final do presente Tratado é a consolidação do processo de integração e cooperaçáo econômica entre a República Federativa do Brasil e a República Argentina. Os territórios dos dois países integraráo um espaço econômico comum, de acordo com os procedimentos e os prazos estabelecidos no presente Tratado". Tratado De Integraçáa, Cooperaçáo E Desenvolvimento Entre O Governo Da República Federativa Do Brasil E O Governo Da República Argentina. Disponível em: http://www.planalto. gov.br/ccivil_03/decreto/1980-1989/D98177.htm Acesso em 29 abril 2015.

4 Além destes documentos, ressaltam-se: Ata para Integração Brasileiro-Argentina, de 29 de julho de 1986; Ata de Amizade Brasileiro-Argentina: Democracia, Paz e Desenvolvimento, de 10 de dezembro de 1986; Comunicado Conjunto sobre o Processo de Integração de 16 de março de 1990. Ata De Buenos Aires. Disponível em: http://dai-mre.serpro.gov.br/atos-internacionais/bilaterais/1990 /b_24_2011-10-17-15-48-37/ . Acesso em 29 abril 2015.

5 O Paraguai foi o último Estado a ser convidado e sua participação se devia, sobretudo, ao importante relacionamento comercial com seus vizinhos e o seu recente processo de redemocratização.

6 Em vigor desde 1\%/01/1995. 
de cunho neoliberal, com um forte teor de instrumentação das chamadas medidas negativas $^{7}$, que importam na derrubada das barreiras para harmonização de legislaçóes. Ou seja, o TA não regulamenta medidas positivas ${ }^{8}$ que impóem a execução de políticas conjuntas destinadas a regular o funcionamento do mercado e maximizar a interdependência. $\mathrm{O}$ Tratado definiu a seguinte estrutura institucional provisória, a quem foi incumbida de efetivar os objetivos da Organização: O Conselho do Mercado Comum, o Grupo do Mercado Comum e uma Secretaria Administrativa.

No mesmo ano de 1991, foi assinado o Protocolo de Brasília que dispunha sobre o esquema de Solução de Controvérsias ${ }^{9}$. E, em 17/12/1994, por força do comando do artigo 18 do Tratado fundador ${ }^{10}$, os Estados-partes começaram a lapidar a forma do bloco através da subscrição do Protocolo de Ouro Preto ${ }^{11}$ (POP), que concedeu personalidade jurídica ao Mercosul ${ }^{12}$, e desenhou a arquitetura institucional definitiva, estruturada em seis órgãos de caráter intergovenamental: I - Conselho do Mercado Comum; II - Grupo do Mercado Comum; III - Comissão de Comércio do Mercosul; IV - Comissão Parlamentar Conjunta; V - Foro Consultivo Econômico e Social; VI - Secretaria Administrativa do Mercosul ${ }^{13}$. Diante da inegável impossibilidade de estabelecer o Mercado Comum no período previamente previsto, o POP reconheceu a necessidade de efetivar a União Aduaneira antes da consolidaçáo do Mercado Comum e, para tal, deveria dotar a OI de uma estrutura institucional compatível com este fim. As dificuldades de realizar o Mercado Comum se deram, em grande medida, pela inexistência de medidas positivas, que efetivamente, só começam a ser pensadas em 2004 com o estabelecimento do Fundo para a Convergência Estrutural e Fortalecimento

7 Integração Negativa é a integração através do desmantelamento das barreiras comerciais entre os Estados partes do processo.

8 Medidas positivas surgem a partir da Integração Positiva. Essa é "uma comunidade de interesses mediante medidas positivas, que normalmente requerem o acordo dos governos nacionais nas instituiçóes comuns e uma explícita legitimação política, como os fundos de reconversão, a redução das assimetrias regionais e o fortalecimento das infraestruturas de modo a favorecer indiretamente o comércio intrazona" CAETANO, Gerardo. VÁZQUEZ, Mariana. VENTURA, Deisy. Reforma institucional del MERCOSUR. Análisis de un reto. In: CAETANO, Gerardo. (Coord.). La reforma institucional del MERCOSUR: Del diagnóstico a las propuestas.Uruguay: Trilce, 2009. p. 43. Disponível em <http:// cefir.org.uy/wp-content/uploads/downloads/2012/05/La-reforma-institucional-del-MERCOSUR.-

Del-diagn\%C3\%B3stico-a-las-propuestas..pdf

9 Em vigor desde 22/04/1993.

10 "ARTIGO 18 - Antes do estabelecimento do Mercado Comum, a 31 de dezembro de 1994, os Estados Partes convocarão uma reuniấo extraordinária com o objetivo de determinar a estrutura institucional definitiva dos órgãos de administração do Mercado Comum, assim como as atribuiçóes específicas de cada um deles e seu sistema de tomada de decisóes."

11 Em vigor em 15/12/1995.

12 Conforme artigo 34 do Tratado de Assunção.

13 Protocolo De Ouro Preto. Disponível em: http://www.mercosur.int/innovaportal/file/721/1/ cmc_1994_protocolo_ouro_preto_es.pdf. Acesso em: Acesso em 29 abril 2015. 
Institucional do Mercosul (FOCEM) ${ }^{14}$. Todavia, os primeiros projetos executados com recursos do Fundo iniciaram em $2007^{15}$.

O caminho trilhado rumo ao aprofundamento político-institucional revela as necessidades de aperfeiçoamento do modelo e a vontade de fazer frente aos desafios que se apresentavam. Do mesmo modo, é necessário enfatizar que o desenvolvimento institucional tem sido uma demanda constante entre os Estados-partes, sobretudo para minimizar a influência do gigante brasileiro no processo e, consequentemente, garantir um certo equilíbrio político. A diferença do peso político-econômico e comercial entre Argentina e, sobretudo, Brasil com relação aos outros membros é tão desproporcional que dificultam negociaçóes e tomadas de decisóes. As assimetrias existentes entre os quatro sócios figuram entre os obstáculos que, em certa medida, dificultam a implantação do mercado comum. A transformação da Secretaria em administrativa em técnica se deu, em grande medida, para dotar o órgão de capacidade de controle político da integração. O Secretariado, único órgão permanente, é hoje o motor da integração.

No caminho do aprofundamento, pode-se se listar a firma do Protocolo de Ushuaia em 24/07/1998, pelos Estados-partes, juntamente com Bolívia e Chile. O Protocolo passa a ser parte integrante do Tratado de Assunção e institui um compromisso democrático e regulamenta a aplicação de procedimentos cabíveis em casos de ruptura da ordem democrática em uma dos Estados-membros. Segundo disposto no artigo $5^{\circ}$, as medidas compreendem "desde a suspensão do direito de participar nos diferentes órgãos dos respectivos processos de integração até a suspensão dos direitos e obrigaçóes resultantes destes processos". ${ }^{16}$

O Protocolo de Olivos ${ }^{17}$, assinado em 18/02/2002, derrogou expressamente o Protocolo de Brasília e estabeleceu um novo sistema de Solução de Controvérsias no Mercosul destinado a garantir a segurança jurídica na sub-região. Criou o Tribunal Arbitral Permanente de Revisão do Mercosul, sediado na cidade de Assunção, e estabeleceu um procedimento de resolução de litígios fortemente inspirado no "Entendimento sobre Solução de Controvérsias da Organização Mundial do Comércio”.

14 FOCEM. Disponível em http://www.planejamento.gov.br/ministerio.asp?index=10\&ler=t3431. Acesso em 15 de maio de 2015.

15 Portanto, 16 anos depois da criação do MERCOSUL. O FOCEM é melhor descrito posteriormente neste trabalho. Focem-Proyectos. Disponível em http://www.mercosur.int/focem/index.php?id=proyectos1. Acesso em 15 de maio de 2015.

16 MERCOSUR. Protocolo De Ushuaia Sobre Compromisso Democrático No Mercosul, Bolívia E Chile. Disponível em: http://www.mercosur.int/msweb/Normas/Tratado\%20e\%20Protocolos/1998_ PROTOCOLO\%20DE\%20USHUAIA-Compromiso\%20democr\%C3\%A1tico_port.pdf . Acesso em 28 abril 2015. Em vigor desde 17/01/2002.

17 Em vigor desde 10/02/2004. Protocolo de olivos para a soluçáo de controvérsias no mercosul. Disponível em: http://www.planalto.gov.br/ccivil_03/_ato2004-2006/2004/decreto/d4982.htm Acesso em 28 abril 2015. Em vigor desde 17/01/2002. 
O reforço institucional também se revelou na conversão da Secretaria Administrativa em uma Secretaria Técnica, com vistas a garantir uma estrutura adequada para consolidar a integração ${ }^{18}$. Em 2005, o Parlamento, sucedeu à Comissão Parlamentar Conjunta e foi incorporado à estrutura institucional do bloco como órgão de caráter independente e autônomo, destinado a ser o representante dos povos. O Parlamento do Mercosul, tal qual o Parlamento Europeu é "composto por representantes eleitos por sufrágio universal, direto e secreto, conforme a legislação interna de cada Estado Parte”. ${ }^{19}$

Atualmente, o design institucional se sofisticou e conta com órgãos definidos em duas categorias: 1) de caráter decisório e executivo - o Conselho do Mercado Comum, o Grupo do Mercado Comum e a Comissão de Comércio; 2) de índoles consultiva, arbitral e assessoria técnico administrativa - o Parlamento, Foro Consultivo Econômico-Social, Tribunal Permanente de Revisão, a Secretaria do Mercosul, o Tribunal Administrativo Laboral, o Alto Representante geral do Mercosul e o Centro Mercosul de Promoção do Estado de Direito.

Dado exposto, observa-se que houve uma sofisticação no aparato orgânico do MERCOSUL, não apenas em termos quantitativos, quanto qualitativos. Paulatinamente se vê a solidificação da autonomia da Organização Internacional, à medida que a sua agenda manifesta a formação da volonté distincte do bloco, em detrimento de posiçóes individualistas nacionais. A agenda inicial - de incumbência dos órgãos de caráter decisório executivo -, carregada de medidas integracionistas negativas, não foi capaz de superar os obstáculos que os próprios Estados impuseram para a formação da União Aduaneira. A segunda geração de órgãos - de índoles consultiva, arbitral e assessoria técnico administrativa - foi a responsável por possibilitar os espaços para a implementação de medidas positivas no MERCOSUL, tornando o design institucional substancialmente mais aprimorado. Em virtude disso, apesar da dependência do modelo intergovernamental, o aumento da autonomia do bloco foi viabilizado com a introdução de agendas que previam medidas positivas que, ao reconhecerem as assimetrias entre as regióes, esculpem a verdadeira face do MERCOSUL. A processo de adoção de medidas positivas será evidenciado na sequência.

\section{A Implantação do FOCEM e o Aprofundamento da Coesão Social}

Diante da dificuldade de consolidação desses objetivos econômicos firmados na carta constitutiva do MERCOSUL, como mencionado anteriormente, os governos dos

18 MERCOSUL/CMC/DEC Nº. 30/02: Transformaçáo Da Secretaria Administrativa Do Mercosul Em Secretaria Técnica. Disponível em: http://www.sice.oas.org/trade/mrcsrs/decisions/dec3002p.asp . Acesso em 28 abril 2015.

19 Protocolo Constitutivo Do Parlamento Do Mercosul. Disponível em: http://www.bcb.gov.br/rex/ sgt4/Ftp/CD\%20Fluxograma/Tratados\%20e\%20Protocolos/Protocolo\%20do\%20Parlamento.pdf Acesso em: Acesso em 28 abril 2015. 
Estados-partes, eleitos a partir de 2003, passaram a imprimir no bloco açôes para o fortalecimento de temas e áreas negligenciadas pelo Tratado de Assunção. Desta forma, as áreas política e social assumiram o espaço das negociaçóes regulatórias no âmbito comercial e econômico. A integração comercial, unicamente, perdeu espaço relativo à tentativa de atenuar as condiçốes assimétricas entre os quatro países membros. Neste sentido, vale ressaltar que o TA não traz no seu corpo o termo "assimetria". E o vocábulo social aparece apenas uma única vez, relacionado à ampliação dos mercados nacionais dos membros ${ }^{20}$.

Deste modo, para consubstanciar a busca da promoção do desenvolvimento no MERSCOSUL e da diminuição das desigualdades entre os países sócios, criou-se, em 2004, o FOCEM. Esse fundo tem como objetivos "promover a convergência estrutural, desenvolver a competitividade e promover a coesão social ${ }^{21}$, em particular das economias menores e regióes menos desenvolvidas; apoiar o funcionamento da estrutura institucional"22. Note-se que a adesão do Paraguai e do Uruguai incrementou os níveis (já existentes no eixo Brasil-Argentina) de assimetria e desigualdade do bloco já que a "diferença entre o peso econômico e político do Uruguai e do Paraguai é maior em relação aos outros membros fundadores". 23

Para o FOCEM está previsto um aporte anual de 100 milhóes durante dez 10 anos, totalizando 1 bilhão de dólares para o financiamento de projetos. Desse total, cabe ao Brasil depositar 70\%, à Argentina 27\%, ao Uruguai 2\% e ao Paraguai 1\%. A distribuição dos recursos para os projetos no Estados dá-se de forma inversa. Aos projetos desenvolvidos no Paraguai estão destinados 48\% dos recursos do fundo, ao Uruguai 32\%, à Argentina $10 \%$ e ao Brasil também $10 \%{ }^{24}$. Atualmente, com a entrada da Venezuela, o orçamento ficou distribuído desta forma: Brasil contribui com US\$ 70 milhóes e recebe US\$11,545 milhôes, a Argentina com US\$ 27 milhóes, e é destinatária de US\$ 11,545 milhôes, a Venezuela US\$ 27 milhóes, e percebe US\$ 11,545 milhóes, o Uruguai US\$ 2 milhões e ganha US\$ 36,944 milhôes e o Paraguai US\$ 1 milhão, e capta US\$ 55,41625.

20 Tratado de Assunção. Disponível em http://www.mercosul.gov.br/tratados-e-protocolos/tratado-deassuncao-1. Acesso em 20 de maio de 2015.

21 Por coesão social, adota-se aqui o conceito utilizado pela Uniāo Europeia: "Exprime a solidariedade entre os Estados-Membros e as regiôes[...], através da qual se favorece o desenvolvimento equilibrado do território comunitário, a redução das diferenças estruturais entre as regiōes [...], bem como a promoção de uma verdadeira igualdade de oportunidades entre as pessoas.”

22 MERCOSUL/CMC/DEC. No 18/05. Integração E Funcionamento Do Fundo Para A Convergência Estrutural E Fortalecimento Da Estrutura Institucional Do Mercosul. Assunção, 2005

23 LOCKHART, Nicolas Pedro Falomir.

24 MERCOSUL/CMC/DEC. No 18/05. Integraçáo E Funcionamento Do Fundo Para A Convergência Estrutural E Fortalecimento Da Estrutura Institucional Do Mercosul. Assunção, 2005

25 MERCOSUL-FOCEM. Decisão CMC No 41/12. Disponível em http://www.mercosul.gov.br/index. php/fundo-para-a-convergencia-estrutural-do-mercosul-focem. Acesso em 15 de maio de 2015. 
Em 2015, o FOCEM irá completar dez anos de operação. O Fundo patrocinou e patrocina, principalmente, projetos sociais, de melhoria da qualidade de vida, de capacitação profissional e de infraestrutura nas regióes menos desenvolvidas dos quatros países membros, com especial atenção ao Paraguai. Os projetos estão divididos nos seguintes Programas: convergência estrutural; desenvolvimento e competitividade; coesão social; e fortalecimento da estrutura institucional e do processo de integração ${ }^{26}$.

O Fundo de Convergência Estrutural do MERCOSUL é um resultado concreto e, ao mesmo tempo, simbólico desta nova perspectiva da integração regional no bloco. Como explica Fabiano de Andrade Correa, as medidas positivas assumiram um espaço que antes era destinado exclusivamente à liberalizaçáo comercial no processo: o de desenvolver os Estados Partes e promover a equidade social. ${ }^{27}$

O advento do FOCEM tem raízes numa nova visão holística para a integração do MERCOSUL ${ }^{28}$. O ex-presidente do Brasil, Luiz Inácio Lula da Silva afirmou em 2008 que:

"O Mercosul não pode reduzir-se apenas a uma zona de livre comércio ou mesmo a uma união aduaneira. Ele tem a vocação de ser um efetivo espaço de integração econômica, política, cultural e de construção de uma nova e ampliada cidadania. Avançamos na direção de uma integração mais solidária, com a criação do Fundo de Convergência Estrutural do Mercosul, voltado para a redução das assimetrias entre os países membros e suas regióes, promovendo a competitividade e a coesão social." 29

Essa visão prevalece entre os sócios do MERCOSUL desde então. Para alcançar seus propósitos, o FOCEM financia projetos que devem se adequar aos seus quatro Programas: I Programa de Convergência Estrutural, II Programa de Desenvolvimento da Competitividade, III Programa de Coesão Social, e IV Programa de Fortalecimento da Estrutura Institucional e do Processo de Integração ${ }^{30}$.

26 PARLASUR. MERCOSUL financia 37 projetos em regiōes menos desenvolvidas do bloco. Disponível em http://www.parlamentodelmercosur.org/innovaportal/v/8462/2/parlasur/mercosul_financia_37_ projetos_em_regi\%F5es_menos_desenvolvidas_do_bloco.htmlAcesso em 15 de maio de 2015 .

27 CORREA, Fabiano de Andrade. A Legal/Institutional Analysis of FOCEM, the MERCOSUR Fund for Structural Convergence.Regional Integration and Development. 2010.

28 A preocupaçáo com a coesáo social e a distribuição dos benefícios da integraçáo sempre esteve presente no processo europeu. Desde o Tratado de Roma (1957), Tratado Constitutivo da Comunidade Econômica Europeia esses pontos já eram abordados. Algo desconsiderado pelo "europeu" Tratado de Assunção.

29 A íntegra dos discursos pode ser consultada em: MRE. Discursos Selecionados do Presidente Luiz Inácio Lula da Silva. FUNAG. Brasília. 2008. Disponível em: <http://www.funag.gov.br/biblioteca/ dmdocuments/0489.pdf>

30 FOCEM. Programas. Disponível em: http://www.mercosur.int/focem/index.php?id=componente-delprograma. Acesso em 15 de maio de 2015. 
Por fim, em relação, por exemplo, com o Programa IV, pode-se entender como o FOCEM auxilia ao fortalecimento institucional do bloco quando vinculamos esse objetivo ao PARLASUL.

O sétimo e o oitavo princípios do PARLASUL afirmam que:

7. A promoção do desenvolvimento sustentável no MERCOSUL e o trato especial e diferenciado para os países de economias menores e para as regióes com menor grau de desenvolvimento. 8. A eqüidade e a justiça nos assuntos regionais e internacionais, e a solução pacífica das controvérsias.

Dada essa aproximação, cabe atualmente ao PARLASUL discutir sobre o atual estágio de reestruturação do FOCEM, uma vez que já foram cumpridas a primeira década de vida prevista dentro do orçamento ${ }^{31}$.

Mas as críticas mais importantes ao Fundo se concentram no seu orçamento modesto. O baixo aporte de capital, atrelado às dificuldades e idiossincrasias políticas e econômicas dos Estados Membros, indicam que, assim como a Integração Negativa não persiste no bloco, a Integração Positiva assume-se claudicante. Os discursos exaltando o FOCEM ${ }^{32}$ quando confrontados com os resultados efetivos e auditorias ${ }^{33}$, evidenciam que o Fundo tem uma maior importância política do que econômica e social para a integração. Pois, apesar da importância dos Projetos para as populaçóes beneficiadas, os resultados positivos não transbordam para todo o processo. Dito de outra forma, os efeitos do FOCEM são localizados e ainda náo suficientes para uma efetiva redução das assimetrias entre as regióes mais pobres.

Todavia, ao FOCEM cabe a função de ser a semente do alvorecer de uma integração pautada pela transferência de renda dos Estados mais fortes às regióes mais debilitadas, de ser o vetor de uma integração que crie agendas regionais descoladas dos interesses voláteis dos governos, principalmente agendas que promovam a coesão e a inserção social das populaçôes mais vulneráveis dos Estados do MERCOSUL. Vistas as nuances do aprofundamento expresso pela sofisticação institucional e pelo adoção da agenda social, passa-se a analisar as peculiaridades do alargamento que demonstram o reduzido grau de elastecimento da Organização.

31 PARLASUL. Mesa Diretora do PARLASUL receberá relatório da Unidade Técnica do FOCEM. Disponível em http://parlamentodelmercosur.org/parlasur/VentanaImprimir.jsp?contentid=8433. Acesso em 15 de maio de 2015.

32 Principalmente no Governo Lula, através do ex-ministro do MRE, Celso Amorim, e do embaixador Samuel Pinheiro Guimarães.

33 EFSUL. Levantamento da Auditoria do FOCEM - Relatório Consolidado. Organização das Entidades Fiscalizadoras Superiores do Mercosul e Associados. 2010. 


\section{Mercosul dos Quatro, dos Cinco...}

Como mencionado anteriormente, o estreitamento dos laços entre Brasil e Argentina cimentou as bases do Mercosul e a OI se transformou em realidade com a adesão dos dois vizinhos do Cone Sul, Uruguai e Paraguai.

Os membros originários, decidiram instituir uma Organização internacional aberta à adesão, "mediante negociação, dos demais países membros da Associação Latino-Americana de Integração", com a ressalva de que as solicitaçóes apenas poderiam "ser examinadas pelos Estados Partes depois de cinco anos de vigência” do TA. Entretanto, o artigo 20 do Tratado abre uma exceção com relação ao prazo de cinco anos para as solicitaçóes de países membros da ALADI que não fizessem "parte de esquemas de integração sub-regional ou de uma associação extra-regional". Importa ressaltar que a aprovação dos pedidos de adesão deve ser objeto de decisão unânime dos Estados-partes.

Ressalvada a exceção, apenas seria factível o alargamento do Mercosul a partir do ano de 1999.

O destravamento jurídico, a subida ao poder por parte de presidentes de concepçóes ideológicas coincidentes que assumiram o desafio de valorizar as pautas sociais coordenadamente, o aprofundamento institucional, entre outros, abriram as portas do bloco para a membresia plena e para o processo de concessão do status de membros associados.

A Venezuela deixou de ser "membro pleno em processo de adesão" para ser membro pleno em 2013, num conturbado e polêmico caso que envolveu a suspenção do Paraguai.

Em 2006, a Venezuela assinou o Protocolo de Adesão ${ }^{34}$, tendo sua vigência estabelecida em 2012. Após uma espera de seis anos, o quinto membro do Mercosul teve a sua aprovação definitiva em meio a uma polêmicas das mais variadas ordens. No caso em tela, os governos da Argentina e do Brasil coincidiram em posiçóes. Em se tratando da quinta economia da América do Sul, Caracas figura como um parceiro estratégico por conta da complementariedade com a indústria pesada brasileira e sua riqueza energética. Para a Argentina, por outro lado, a entrada da Venezuela se traduz numa força capaz de contrabalançar o peso do Brasil.

Importa ressaltar que a Venezuela viu no Cone Sul, um aliado às suas aspiraçóes bolivarianas e uma maneira de redirecionar o fluxo comercial que perdera após a saída, por incompatibilidades ideológicas, da Comunidade Andina. Outrossim, o modelo ideal de integração para o então presidente Hugo Chávez era aquele demonstrado no âmbito das

34 MERCOSUR. Protocolo De Adesão Da República Bolivariana De Venezuela Ao Mercosul. Disponível em: http://www.mercosur.int/innovaportal/file/4002/1/2006_protocolo_pt_adhesionvenezuela. pdf. Acesso em: Acesso em 29 abril 2015. 
iniciativas que criaram a Aliança Bolivariana para os Povos da Nossa América (ALBA) ${ }^{35}$. Portanto, a ALBA, atuante na seara social e com premissas de trocas solidárias entre os Estados $^{36}$, refletiria os desejos do líder venezuelano de como deveria ser a união dos países da América Latina. Já o projeto do Cone Sul serviria mais como sustentação política e econômica. Outro ponto relevante é que a Venezuela, desde logo, manifestou interesse no FOCEM, tanto como beneficiária como contribuinte. Neste sentido, decidiu-se que Caracas contribuiria com 27 milhóes de dólares por ano ao FOCEM. ${ }^{37}$ O Protocolo de Adesão, no seu artigo $8^{\circ}$ demostra o compromisso das partes contratantes em promover a inclusão social e "assegurar condições de vida digna para seus povos" ${ }^{3}$.

A aprovação legislativa para a acessão venezuelana foi mais rápida na Argentina e no Uruguai. Entretanto, o processo ganhou uma tonalidade político-partidária de oposição ao governo de Hugo Chávez táo forte nos legislativos brasileiro e paraguaio, a ponto de paralisar todas as tratativas de internalização do Protocolo de Adesão. O Senado brasileiro só aprovou o Protocolo de Adesão em 15 de dezembro de 2009 numa votação apertada, sendo 35 votos favoráveis e 27 contrários. Já em Assunção, a bancada oposicionista bloqueou as tentativas de incorporação de Caracas.

Os representes políticos paraguaios mantinham duras restriçôes à entrada do país governado por Hugo Chávez. As justificativas orbitavam nos argumentos de que a Venezuela não era, seguramente, democrática. Disto decorre o prolongamento da votação no Congresso do Paraguai ${ }^{39}$. Na sequência, em 29 de junho de 2012, o Paraguai foi suspenso dos direitos de participar nos órgãos do MERCOSUL pela violação ao artigo $7^{\circ}$ do Protocolo de Ushuaia sobre o compromisso democrático, em função da destituição controversa do então presidente Fernando Lugo ${ }^{40}$. Logo em seguida, numa decisão política polêmica, os presidentes de Argentina, Brasil e Uruguai, com o quarto país-membro suspenso,

35 A ALBA atualmente é composta por Antígua e Barbuda, Bolívia, Cuba, Dominica, Equador, Nicarágua, São Vicente e Granada e Venezuela.

36 ALBA. Acuerdo Entre Venezuela Y Cuba Para La Aplicación Del Alba. Disponível em http://www. portalalba.org/index.php/2014-03-29-22-04-24/documentos/1220-2004-12-14-i-cumbre-la-habanacuba-acuerdo-entre-venezuela-y-cuba-para-la-aplicacion-del-alba. Acesso em 15 de maio de 2015.

37 Decisão CMC No 41/12. Disponível em http://www.mercosur.int/innovaportal/file/6016/1/2012dec_041_2012_pt__adesao_venezuela_ao_focem.pdf. Acesso em 15 de maio de 2015.

38 Protocolo De Adesáo Da República Bolivariana De Venezuela Ao Mercosul. Disponível em: http:// www.mercosur.int/innovaportal/file/4002/1/2006_protocolo_pt_adhesionvenezuela.pdf . Acesso em 29 abril 2015.

39 PAZ, Domingos. Ruptura democrática no e do Mercosul: a "suspensão" do Paraguai e "adesão" da Venezuela. Rev. Política Externa. Vol. 21 no 3 - Jan/Fev/Mar 2013

40 Os efeitos da suspensão foram cessados em 15 de agosto de 2013, após a posse do novo presidente eleito. Decisão Sobre O Fim Da Suspensáo Do Paraguai No Mercosul Em Aplicaçáo Do Protocolo De Ushuaia Sobre Compromisso Democrático. Disponível em: http://www.mercosur.int/innovaportal/ file/5618/1/declarac\%E3o_paraguai_pt.pdf. Acesso em 05 maio 2015. 
aprovaram a entrada definitiva da Venezuela ao MERCOSUL ${ }^{41}$. As principais críticas à votação que definiu o ingresso venezuelano deitava raízes nos seguintes tópicos: 1) no descumprimento do mandamento do Tratado de Assunção que determina a participação de todos os Estados-partes nas deliberaçóes sobre alargamento. Ou seja, a aprovação se deu à revelia do Paraguai; 2) $\mathrm{O}$ procedimento que conduziu à suspensão de Assunção, desconsiderou alguns termos do Protocolo de Ushuaia, no que se refere às consultas entre os Estados e com o país afetado; 3) A não-satisfação por parte da Venezuela, de todos os requisitos de harmonização da legislação aduaneira, essenciais para entrada na Organização Internacional.

Após um momento de estranhamento entre os sócios e, inclusive, a ameaça do Paraguai de retirar-se do bloco e de insinuaçóes de aproximação à Aliança do Pacífico, em dezembro de 2013, a Câmara dos Deputados do Paraguai, finalmente, levou para votação o Protocolo de adesão e aprovou a acessão da Venezuela. No início deste mesmo ano o país realizou um pleito que elegeu como presidente Horácio Cartes. O ostracismo forçado do Paraguai foi suspenso em 2014, graças a "restauração da ordem democrática no país" "².

A Bolívia teve seu caminho para a afiliação inaugurado em 2012, com previsão de concretização em quatro anos ${ }^{43}$. Este país andino é estratégico para a integração, entre outras razóes, porque possui grandes reservas de hidrocarbonetos.

Assim, a Bolívia tornou-se o sexto membro a assinar o Protocolo de Adesão $^{44} \mathrm{em}$ 07 de dezembro de 2012, num processo que ainda se encontra em curso, dependente de aprovação doméstica de Brasil, Argentina e Paraguai. Na última Cúpula do Mercosul, em dezembro de 2014, não houve avanços à adesão plena da Bolívia. Os Estados-partes prometeram estudar o pedido do Paraguai de se estabelecer Zonas Francas no bloco, entre outras condiçôes de comércio, para ratificar a entrada da Bolívia ${ }^{45}$.

41 GARCIA, Marco Aurélio. Paraguai, Brasil e o MERCOSUL. Rev. Política Externa. Vol. 21 no 3 - Jan/ Fev/Mar 2013

42 MERCOSUR-IPPDH. Cúpula de Chefes de Estado do MERCOSUL e Estados Associados Disponível em: http://www.ippdh.mercosur.int/pt-br/cupula-de-chefes-de-estado-do-mercosul-eestados-associados/. Acesso em 20 maio de 2015.

43 Protocolo De Adesão Do Estado Plurinacional Da Bolívia Ao Mercosul. Disponível em: http:// www.itamaraty.gov.br/index.php?option=com_content\&view=article\&id=3248:protocolo-de-adesaodo-estado-plurinacional-da-bolivia-ao-mercosul\&catid=42\&lang=pt-BR\&Itemid=280. Acesso em 14 de abril de 2015.

44 Protocolo De Adesão Do Estado Plurinacional Da Bolívia Ao Mercosul. Disponível em: http:// www.mercosur.int/innovaportal/file/4002/1/protocolo_adesao_bolivia_ao_mercosul.pdf. Acesso em: Acesso em 29 abril 2014.

45 ITAMARATY. Comunicado Conjunto De Las Presidentas Y Los Presidentes De Los Estados Partes Del Mercosur Y Estados Asociados. Disponível em: http://www.itamaraty.gov.br/index. php?option=com_content\&view=article\&id=6238:documentos-aprovados-na-xlvii-cupulade-chefes-de-estado-do-mercosul-e-estados-associados-parana-argentina-17-de-dezembro-de$2014 \&$ catid $=42 \&$ Itemid $=280 \&$ lang=pt $-B R$. Acesso em 14 de maio de 2015. 
Da mesma forma que o caso venezuelano o Protocolo de Adesão da Bolívia, no seu artigo $9^{\circ}$ revela o compromisso das partes contratantes em promover a inclusão social e vida digna para seus povos" ${ }^{36}$.

A incorporação destes dois Estados conferiu um caráter quase continental ao Mercosul.

Além da categoria de membro pleno, um Estado pode solicitar a participação no Mercosul na condição de associado ou observador. A Resolução n. 18/04 do Conselho do Mercado Comum dispóe que a qualidade de associados deve ser exclusiva dos membros da ALADI "com os quais o MERCOSUL tenha assinado Acordos de Livre Comércio" e, após a "protocolização do referido Acordo na ALADI". A solicitação deve, ainda, ser encaminhada "ao Conselho do Mercado Comum, por intermédio da Presidência Pro Tempore do MERCOSUL”. O Estado em questão deve aderir ao Protocolo de Ushuaia sobre Compromisso Democrático no MERCOSUL, Bolívia e Chile e firmar, igualmente, à "Declaração Presidencial sobre Compromisso Democrático no MERCOSUL”47.

Ou seja a condição de associada é reservado a naçóes que tenham assinado previamente um "Acordo de Complementação Econômica", com o Mercosul.

Nestes acordos é estabelecido um Programa de Liberalização Comercial que possibilitará a formação de uma área de livre comércio entre as Partes Contratantes, mediante o alargamento e a diversificação do intercâmbio comercial e a eliminação das barreiras (tarifárias e não-tarifárias) que atinjam o comércio recíproco.

Tal condição permite o país a participar na qualidade de convidado nas reuniōes dos órgãos para negociar temas de interesse comum e a assinar acordos sobre matérias comuns $^{48}$.

46 MERCOSUR. Protocolo de adesão do estado plurinacional da bolívia ao mercosul. Disponível em: http://www.mercosur.int/innovaportal/file/4002/1/protocolo_adesao_bolivia_ao_mercosul.pdf. Acesso em: Acesso em 29 abril 2015.

47 Art. 3 - A condição de Estado Associado será atribuída por Decisão do Conselho. MERCOSUL/ CMC/DEC. No 18/04: REGIME DE PARTICIPAÇĀO DOS ESTADOS ASSOCIADOS AO MERCOSUL. Disponível em: http://www.sice.oas.org/trade/mrcsrs/decisions/dec1804p.asp . Acesso em 28 abril 2015.

48 "Art. 5 - Os Estados Associados do MERCOSUL estão convidados a participar em todas as reuniôes do Foro de Consulta e Concertação Política em termos relacionados com a agenda de interesse comum.

Em todos os casos a participação dos Estados Associados, assim como a agenda dos temas a tratar, deverá ser aprovada pelos Coordenadores Nacionais dos quatro Estados Partes do MERCOSUL do órgão de que se trate e posto em conhecimento do órgáo decisório correspondente, quando seja o caso.

Art. 6-Quando os Estados Associados participarem de reuniōes dos órgãos do MERCOSUL a reuniāo se desenvolverá em duas sessōes, sendo a primeira entre os Estados Partes do MERCOSUL". MERCOSUL/ CMC/DEC. No 18/04: REGIME DE PARTICIPAÇÁO DOS ESTADOS ASSOCIADOS AO MERCOSUL. Disponível em: http://www.sice.oas.org/trade/mrcsrs/decisions/dec1804p.asp . Acesso em 28 abril 2014. 
Atualmente, os seguintes Estados são os beneficiários do estatuto de associados: Chile $e^{49}$ (1996), Peru ${ }^{50}$ (2003), Colômbia e Equador ${ }^{51}$ (2004), Guiana ${ }^{52}$ e Suriname $^{53}$ (2013). A Nova Zelândia e o México participam na condição de observadores, ou seja, sem direito a voz ou voto.

Peru e Colômbia muito provavelmente não serão membros plenos, pois participam, juntamente com México e Chile, da Aliança do Pacífico (AP). A AP é um arranjo, prioritariamente, de livre-comércio ${ }^{54}$. Essa característica choca-se com os requisitos de adesão do MERCOSUL. A adoção de uma Tarifa Externa Comum intra-bloco, por exemplo, não admite acordos comerciais sem a presença de todos os Estados-membros.

Dado o exposto, percebe-se que o MERCOSUL possui seis Estados-membros, seis associados e dois observadores. A ampliação colocou sobre a mesa o debate sobre o aprofundamento. Argentina, Uruguai e Paraguai eram mais partidários da consolidação do modelo antes do alargamento, ainda que não apresentem restriçóes insuperáveis. Para o Brasil, uma ação não exclui a outra, uma vez que a adesão de novos Estados poderia conferir um dinamismo ao bloco mesmo tempo que ampliar a zona de influência de Brasília na América do Sul.

Uma breve análise sobre a capacidade do bloco de atrair novos membros parte de duas frentes: as condiçóes de atração e as reticências dos próprios Estados-membros em ratificar a entrada de novos sócios.

Em termos de instrumentos de atração, o MERCOSUL dá uma salto qualitativo quando insere no seu bojo novos temas. Segundo Samuel Pinheiro Guimarães, o Brasil imprimiu, enquanto país mais importante do bloco, um novo modo de relacionamento com os sócios, baseado no reconhecimento das assimetrias. Isso favorece a busca de uma

49 Acordo de Complementaçáo Econômica Mercosul-Chile (ACE No35; CMC No3/96). Disponível em: http:/www.planalto.gov.br/ccivil_03/decreto/1996/D2075.htm Acesso em: 30 abril 2015.

50 Acordo de Complementação Econômica n 58, bem como de seu Segundo Protocolo Adicional, entre os Governos da República Argentina, da República Federativa do Brasil, da República do Paraguai, da República Oriental do Uruguai, Estados Partes do MERCOSUL, e o Governo da República do Peru. Disponível em: http://www.planalto.gov.br/ccivil_03/_Ato2004-2006/2005/Decreto/D5651.htm. Acesso em: 02 maio 2015.

51 Acordo de Complementação Econômica no 59, entre os Governos da República Argentina, da República Federativa do Brasil, da República do Paraguai, da República Oriental do Uruguai, Estados Partes do Mercosul, e os Governos da República da Colômbia, da República do Equador, da República Bolivariana da Venezuela, Países Membros da Comunidade Andina. Disponível em: http://www.planalto.gov.br/ ccivil_03/_Ato2004-2006/2005/Decreto/D5651.htm. Acesso em: 02 maio 2015.

52 Acordo De Associação Entre O Mercosul E A República Cooperativista Da Guiana. Disponível em: http://www.mercosur.int/innovaportal/file/4827/1/2013_acordo_mercosul-guaiana_pt.pdf._Acesso em 02 maio 2015.

53 Acordo De Associaçáo Entre O Mercosul E O Suriname. Disponível em: http://www.mercosur.int/ innovaportal/file/5564/1/2013_acordo_mercosul-suriname_pt.pdf. Acesso em 02 maio 2015.

54 Declaracion Presidencial Sobre La Alianza Del Pacífico. Disponível em: http://alianzapacifico.net/ documents/AP_Declaracion_Lima_I_Cumbre.pdf. Acesso em 14 de maio de 2015. 
melhor integração mais justa, pois está pautada no reconhecimento de níveis diferentes de desenvolvimento ${ }^{55}$. Nas palavras do autor:

A generosidade dos países maiores e mais desenvolvidos é sempre mencionada pelo Presidente Lula como [...] essencial para o êxito do processo de integração do Mercosul e da América do Sul. Esta generosidade deve se traduzir pelo tratamento diferencial, sem exigência de reciprocidade, em relação a todos os países da América do Sul que estejam engajados no processo de integração regional, nas áreas do comércio de bens, de serviços, de compras governamentais, de propriedade intelectual etc. Isto é, o Brasil deve estar disposto a conceder tratamento mais vantajoso sem reciprocidade a todos os seus vizinhos, em especial àqueles de menor desenvolvimento relativo, aos países mediterrâneos e aos países de menor PIB per capita. O Brasil, apesar de ser o maior país da região, não acredita ser possível desenvolver-se isoladamente sem que toda a região se desenvolva econômica e socialmente e se assegure razoável grau de estabilidade política e segurança. Assim, a solidariedade nos esforços de desenvolvimento e de integração é uma ideia central na estratégia brasileira na América do Sul, assim como a ideia de que este processo é um processo entre parceiros iguais e soberanos, sem hegemonias nem lideranças. ${ }^{56}$

No entanto, o não alcance dos objetivos econômicos dispostos no TA contribuem para a instabilidade do processo. Os vizinhos observam que os entraves do MERCOSUL residem nos próprios membros. Nos primeiros dez anos do bloco houve a tentativa de se formar um Mercado Comum efetivo, com Tarifas Externas Comuns (TECs) e harmonização de políticas econômicas e fiscais. Tais objetivos, que constam no Tratado de Assunção (TA), nunca foram alcançados. O bloco não chega a ser sequer uma Área de Livre Comércio devido ao protecionismo unilateral de Brasil e Argentina ${ }^{57}$.

Já as forças de repulsa ao MERCOSUL têm origem na política internacional da América do Sul. Externamente, os membros do MERCOSUL tem de lidar com vizinhos que se associam a um projeto de integração voltado para a liberalização comercial em primeiro plano, mas sem o aprofundamento institucional para o avanço às etapas mais ambiciosas. Neste caso, se adequam Chile, Colômbia e Peru. Ambos possuem acordos de livre comércio bilaterais com vários países no mundo e adotam essa estratégia para uma melhor inserção regional e internacional ${ }^{58}$.

55 GUIMARÃES, Samuel Pinheiro. O Mundo Multipolar e a Integraçáo Sul-Americana. Temas e Matizes. 2008

56 Idem

57 CARTA CAPITAL. Mujica diz que Argentina atrapalha Mercosul. Disponível em http://www. cartacapital.com.br/internacional/mujica-diz-que-argentina-atrapalha-mercosul-5371.html. Acesso em 15 de maio de 2015.

58 LOPES, Renata Rossetto; CARVALHO, Carlos Eduardo. Acordos bilaterais de comércio como estratégia de inserção regional e internacional do Chile. Contexto int., Rio de Janeiro, v. 32, n. 2, p. 643-693, Dec. 2010 . 
Do ponto de vista endógeno, há dificuldades, até mesmo entre os sócios, em acelerar o processo de alargamento. A entrada do primeiro membro não originário deu-se de forma conturbada e sem o consenso ${ }^{59}$ dos quatro fundadores. Conforme mencionado, na época o Paraguai, em regime de suspensão do MERCOSUL, chegou a cogitar uma aproximação com a Aliança do Pacífico ${ }^{60}$. Essas divergências devem-se há falta de coordenação e identidade política entre os representantes eleitos em prol da integração. Neste sentido, as partes vislumbram o MERCOSUL como um meio e náo um fim em si mesmo. As vantagens para as unidades políticas prevalecem sobre a construção de um interesse verdadeiramente regional. Corroboram esta afirmação as recentes exigências econômicas do Paraguai para ratificar o ingresso da Bolívia e a dilação de Brasil e Argentina.

Portanto, no atual cenário do MERCOSUL e do seu entorno, tem-se Estados, nomeadamente, Bolívia e Equador, que vislumbram no bloco um espaço integrado funcional impulsionador de seus projetos de desenvolvimento social e econômico e suas aderências políticas regionais e internacionais. Por outro lado, há Estados, a exemplo de Chile, Peru e Colômbia, que percebem o MERCOSUL como uma via de relacionamento ${ }^{61}$ político e econômico, mas sem assumir compromissos que forcem uma alteração significativa nos seus comportamentos de política externa.

\section{Conclusões}

As dificuldades para o alcance dos objetivos econômicos básicos no Tratado de Assunção, fizeram do MERCOSUL, atualmente, um bloco com importância mais política que econômica. Não obstante, após a aceitaçáo de que as regióes possuem assimetrias de desenvolvimento, os Chefes de Estado e de Governo imprimem um novo rumo ao processo de integração.

Os objetivos iniciais do MERCOSUL, já expostos neste artigo, portanto, são de ordem econômica e comercial. Apesar disso, na segunda década de vida do bloco percebe-se que o escopo social e a aceitação das desigualdades entre os sócios são inseridos nas agendas das Cúpulas dos Chefes de Estado. O artigo explorou essa mudança holística e seu impacto na trajetória do MEROSUL.

Esse novo fôlego ao MERCOSUL serviu para a criação de novos espaços institucionais para atenderem às demandas dessas novas agendas, conferindo aumento de autonomia à Organização Internacional e criando um novo contexto de interesses para a atração de novos Estados-membros.

59 Não de acordo, portanto, com as regras de adesão do MERCOSUL.

60 ICTDS. Paraguai reafirma intenção de ingresso como observador na Aliança do Pacífico. Disponível em http://www.ictsd.org/bridges-news/pontes/news/paraguai-reafirma-inten\%C3\%A7\%C3\%A3o-deingresso-como-observador-na-alian\%C3\%A7a-do. Acesso em 15 de maio de 2015.

61 E não de integraçâo, no sentido do conceito já apresentado aqui. 
O itinerário do bloco, portanto, não seguiu uma lógica progressiva que culminaria na formação de um Mercado Comum entre os sócios. Neste sentido, ressalta-se a ausência no espírito do Tratado de qualquer menção a açóes ou contingências que levassem a criação de Fundos estruturais que caracterizassem uma a necessidade de Medidas Positivas. Os Estados Partes vislumbraram com a criação do bloco uma melhor inserção conjunta no cenário econômico internacional, que à época se caracterizava pela "consolidação de grandes espaços econômicos"'62.

Portanto, em nenhum momento está explícito que medidas positivas seriam utilizadas para impulsionar ou facilitar o processo. Tampouco há o reconhecimento das assimetrias e desigualdades no nível de desenvolvimento dos Estados Partes. O Tratado de Assunção é um acordo quadro que persegue objetivos na seara econômica.

O contexto mundial no qual surgiu o Mercosul é grande influenciador do tipo ideal de integração adotado. A despeito de ser intergovernamental, o itinerário que o bloco do Cone Sul se propôs a seguir era o mesmo dos blocos comerciais que ganharam proeminência após a queda do muro de Berlim e avanço da globalização.

Desta forma, não obstante a vontade representada nos documentos oficiais que deram origem ao bloco, os objetivos comerciais não se concretizaram. Mas a conscientização dos problemas sociais e dos desníveis estruturais entre as regióes vieram à tona como empecilhos à integração, fazendo com que os governos seguintes colocassem em xeque o modelo adotado.

É nesse contexto que emerge o FOCEM e demais compromissos com a coesão social. Outrossim, essas iniciativas se tornaram as reais dinâmicas do bloco.

A execução dos projetos do FOCEM não está acompanhada por contrapartidas nacionais benéficas à integração negativa. Nota-se, até, uma certa indiferença dos tomadores de decisóes nacionais em relação aos objetivos econômicos. No entanto, o fundo contribui para a integração ao ser um instrumento que demonstra um reforço institucional no bloco em questóes de assimetrias estruturais, mas com efeitos simbólicos devido a sua limitação orçamentária. O FOCEM indica, ainda, a existência de uma integração que destoa daquela puramente presente no Tratado de Assunção. Ao inserir o tema de redução das assimetrias no processo, os Estados-partes imprimem no MERCOSUL a tentativa de desenvolvimento compartilhado na região e mantêm a integração ativa.

A Integração Positiva, entendida aqui, entre outras características, como medidas da integração para o desenvolvimento dos Estados-membros, é, portanto, um meio político importante para trazer previsibilidade e visibilidade à integração regional ao garantir que

62 Tratado de Assunção. Disponível em http://www.mercosul.gov.br/tratados-e-protocolos/tratado-deassuncao-1. Acesso em 20 de maio de 2015. 
esse processo irá além da integração negativa - fim das barreiras comerciais - e da criação de instituiçóes e acordos que regulariam o mercado comum a ser formado, mesmo sem afetivamente atingir os possíveis objetivos de redução de assimetrias e convergência estrutural.

Ressalta-se, ainda, que o FOCEM é importante tanto para a integração positiva quanto para a integração negativa do MERCOSUL. Evidencia-se que o Fundo fomenta a integração política e institucional pelo simples fato de lançar esperanças benéficas para os tomadores de decisáo e à sociedade civil dos Estados.

\section{Referências}

ALBA. Acuerdo Entre Venezuela Y Cuba Para La Aplicación Del Alba. Disponível em http://www.portalalba.org/index.php/2014-03-29-22-04-24/documentos/1220-2004-12-14-i-cumbre-la-habana-cuba-acuerdo-entre-venezuela-ycuba-para-la-aplicacion-del-alba. Acesso em 15 de maio de 2015.

ALIANZA DEL PACIFICO. Declaracion Presidencial Sobre La Alianza Del Pacífico.

Disponível em: http://alianzapacifico.net/documents/AP_Declaracion_Lima_I_ Cumbre.pdf. Acesso em 14 de maio de 2015.

BCB BRASIL. Protocolo Constitutivo Do Parlamento Do Mercosul. Disponível em: http://www.bcb.gov.br/rex/sgt4/Ftp/CD\%20Fluxograma/Tratados\%20e\%20Protocolos/Protocolo\%20do\%20Parlamento.pdf Acesso em: Acesso em 28 abril 2015.

BRASIL. Tratado De Integraçáo, Cooperação E Desenvolvimento Entre O Governo Da República Federativa Do Brasil E O Governo Da República Argentina. Disponível em: http://www.planalto.gov.br/ccivil_03/decreto/1980-1989/D98177. htm Acesso em 29 abril 2015.

CAETANO, Gerardo. VÁZQUEZ, Mariana. VENTURA, Deisy. Reforma institucional del MERCOSUR. Análisis de un reto. In: CAETANO, Gerardo. (Coord.). La reforma institucional del MERCOSUR: Del diagnóstico a las propuestas.Uruguay: Trilce, 2009. p. 43. Disponível em <http://cefir.org.uy/wp-content/uploads/downloads/2012/05/La-reforma-institucional-del-MERCOSUR.-Del-diagn\%C3\%B3stico-a-las-propuestas..pdf

CARTA CAPITAL. Mujica diz que Argentina atrapalha Mercosul. Disponível em http://www.cartacapital.com.br/internacional/mujica-diz-que-argentina-atrapalhamercosul-5371.html. Acesso em 15 de maio de 2015.

CORREA, Fabiano de Andrade. A Legal/Institutional Analysis of FOCEM, the MERCOSUR Fund for Structural Convergence.Regional Integration and Development. 2010. 
EFSUL. Levantamento da Auditoria do FOCEM - Relatório Consolidado. Organização das Entidades Fiscalizadoras Superiores do Mercosul e Associados. 2010.

FOCEM. Programas. Disponível em: http://www.mercosur.int/focem/index.php?id=componente-del-programa. Acesso em 15 de maio de 2015.

GARCIA, Marco Aurélio. Paraguai, Brasil e o MERCOSUL. Rev. Política Externa. Vol. 21 no 3 - Jan/Fev/Mar 2013.

GUIMARÃES, Samuel Pinheiro. O Mundo Multipolar e a Integração Sul-Americana. Temas e Matizes. 2008.

HERZ, Mônica; HOFFMANN, Andrea Ribeiro. Organizaçóes internacionais: história e práticas. Rio de Janeiro: Campus, 2004.

ICTDS. Paraguai reafirma intenção de ingresso como observador na Aliança do Pacífico. Disponível em http://www.ictsd.org/bridges-news/pontes/news/paraguai -reafirma-inten $\%$ C3\%A7\%C3\%A3o-de-ingresso-como-observador-na-alian\%C3\%A7a-do. Acesso em 15 de maio de 2015.

ITAMARATY. Comunicado Conjunto De Las Presidentas Y Los Presidentes De Los Estados Partes Del MercosurY Estados Asociados. Disponível em: http://www.itamaraty.gov.br/index.php?option=com_content\&view=article\&id=6238:documentos-aprovados-na-xlvii-cupula-de-chefes-de-estado-do-mercosul-e-estados-associados-parana-argentina-17-de-dezembro-de-2014\&catid=42\&Itemid=280\&lang=pt-BR. Acesso em 14 de maio de 2015.

LOCKHART, Nicolas Pedro Falomir. L'élargissement du Mercosur: accès acidentel du Venezuela et autres processus d'adhésion en cours. Centre d'études interaméricaines - Chronique Avril 2014. Disponível em: http://www.cms.fss.ulaval.ca/recherche/upload/cei/fichiers/acces_du_venezuela_au_mercosur_nfl.pdf Acesso em: 28 abril 2014.

LOPES, Renata Rossetto; CARVALHO, Carlos Eduardo. Acordos bilaterais de comércio como estratégia de inserção regional e internacional do Chile. Contexto int., Rio de Janeiro, v. 32, n. 2, p. 643-693, Dec. 2010 .

MERCOSUL. Tratado de Assunção. Disponível em http:/www.mercosul.gov.br/tratados-e-protocolos/tratado-de-assuncao-1. Acesso em 20 de maio de 2015.

MERCOSUL. FOCEM. Decisão CMC No 41/12. Disponível em http://www.mercosul. gov.br/index.php/fundo-para-a-convergencia-estrutural-do-mercosul-focem. Acesso em 15 de maio de 2015.

MERCOSUL/CMC/DEC. No 18/05. Integração E Funcionamento Do Fundo Para A Convergência Estrutural E Fortalecimento Da Estrutura Institucional Do Mercosul. Assunção, 2005. 
MERCOSUL/CMC/DEC. No 18/04: Regime De Participação Dos Estados Associados Ao Mercosul. Disponível em: http://www.sice.oas.org/trade/mrcsrs/decisions/ dec1804p.asp . Acesso em 28 abril 2015.

MERCOSUL/CMC/DEC N. 30/02: Transformaçáo Da Secretaria Administrativa Do Mercosul Em Secretaria Técnica. Disponível em: http://www.sice.oas.org/trade/mrcsrs/decisions/dec3002p.asp. Acesso em 28 abril 2015.

MERCOSUR-IPPDH. Cúpula de Chefes de Estado do MERCOSUL e Estados Associados Disponível em: http://www.ippdh.mercosur.int/pt-br/cupula-de-chefes-de -estado-do-mercosul-e-estados-associados/. Acesso em 20 maio de 2015.

MERCOSUR. Protocolo De Ouro Preto. Disponível em: http://www.mercosur.int/innovaportal/file/721/1/cmc_1994_protocolo_ouro_preto_es.pdf. Acesso em: Acesso em 29 abril 2015.

MERCOSUR. Protocolo de adesáo do estado plurinacional da bolívia ao mercosul. Disponível em: http://www.mercosur.int/innovaportal/file/4002/1/protocolo_adesao_bolivia_ao_mercosul.pdf. Acesso em: Acesso em 29 abril 2015.

MERCOSUR. Focem-Proyectos. Disponível em http://www.mercosur.int/focem/index. php?id=proyectos1. Acesso em 15 de maio de 2015.

MERCOSUR. Protocolo De Ushuaia Sobre Compromisso Democrático No Mercosul, Bolívia E Chile. Disponível em: http://www.mercosur.int/msweb/Normas/ Tratado\%20e\%20Protocolos/1998_PROTOCOLO\%20DE\%20USHUAIACompromiso\%20democr\%C3\%A1tico_port.pdf. Acesso em 28 abril 2015.

MERCOSUR. CMC No 41/12. Disponível em http://www.mercosur.int/innovaportal/ file/6016/1/2012-dec_041_2012_pt_adesao_venezuela_ao_focem.pdf. Acesso em 15 de maio de 2015.

MERCOSUR. Protocolo De Adesáo Da República Bolivariana De Venezuela Ao Mercosul. Disponível em: http://www.mercosur.int/innovaportal/file/4002/1/2006_ protocolo_pt_adhesionvenezuela.pdf. Acesso em 29 abril 2015.

MERCOSUR. Decisão Sobre O Fim Da Suspensão Do Paraguai No Mercosul Em Aplicaçáo Do Protocolo De Ushuaia Sobre Compromisso Democrático. Disponível em: http://www.mercosur.int/innovaportal/file/5618/1/declarac\%E3o_paraguai_pt.pdf. Acesso em 05 maio 2015.

MERCOSUR. Acordo De Associação Entre O Mercosul E A República Cooperativista Da Guiana. Disponível em: http://www.mercosur.int/innovaportal/ file/4827/1/2013_acordo_mercosul-guaiana_pt.pdf. Acesso em 02 maio 2015.

MERCOSUR. Acordo De Associação Entre O Mercosul E O Suriname. Disponível em: http:/www.mercosur.int/innovaportal/file/5564/1/2013_acordo_mercosul-suriname_pt.pdf. Acesso em 02 maio 2015. 
MINISTÉRIO DO PLANEJAMENTO DO BRASIL. FOCEM. Disponível em http:// www.planejamento.gov.br/ministerio.asp?index=10\&ler=t3431. Acesso em 15 de maio de 2015.

MRE. Ata De Buenos Aires. Disponível em: http://dai-mre.serpro.gov.br/atos-internacionais/bilaterais/1990/b_24_2011-10-17-15-48-37/. Acesso em 29 abril 2015.

MRE. Discursos Selecionados do Presidente Luiz Inácio Lula da Silva. FUNAG. Brasília. 2008. Disponível em: http://www.funag.gov.br/biblioteca/dmdocuments/0489.pdf

PARLASUR. MERCOSUL financia 37 projetos em regióes menos desenvolvidas do bloco. Disponível em http://www.parlamentodelmercosur.org/innovaportal/v/8462/2/parlasur/mercosul_financia_37_projetos_em_regi\%F5es_menos_desenvolvidas_do_bloco.htmlAcesso em 15 de maio de 2015.

PARLASUL. Mesa Diretora do PARLASUL receberá relatório da Unidade Técnica do FOCEM. Disponível em http://parlamentodelmercosur.org/parlasur/VentanaImprimir.jsp? contentid=8433. Acesso em 15 de maio de 2015.

PAZ, Domingos. Ruptura democrática no e do Mercosul: a "suspensão" do Paraguai e “adesão” da Venezuela. Rev. Política Externa. Vol. 21 n 3 - Jan/Fev/Mar 2013.

PLANALTO. Protocolo de olivos para a soluçáo de controvérsias no mercosul. Disponível em: http://www.planalto.gov.br/ccivil_03/_ato2004-2006/2004/decreto/ d4982.htm . Acesso em 28 abril 2015.

PLANALTO. Acordo de Complementação Econômica Mercosul-Chile (ACE No35; CMC No3/96). Disponível em: http:/www.planalto.gov.br/ccivil_03/decreto/1996/D2075.htm Acesso em: 30 abril 2015. 